$$
\begin{array}{ll}
\text { DOE/PC/89757--2 } \\
\text { DEE } 2040022
\end{array}
$$

DE-AC22-89PC89757-2

\title{
THERMODYNAMICS AND SURFACE STRUCTURE OF COALS
}

\author{
Quarterly Report for the Reriod \\ January 1, 1990 to April 1, 1990
}

Patrick C. Wernett, James Maioriello, and John W. Larsen

\author{
Department of Chemistry \\ Lehigh University \\ Bethlehem, Pa. 18015
}

\author{
PREPARED FOR THE UNITED STATES DEPARTMENT OF ENERGY \\ Under contract DE-AC22-89PC89757
}

\section{DISCLAIMER}

This neport wass f epared as an account of work sponsored by an agency of the United States Government. Neither the United States Government nor any agency thereof, nor any of their employees, makes any warranty, express or implied, or assumes any legal liability or responsibility for the accuracy, completeness, or usefulness of any information, apparatus, product or process disclosed, or represents that its use would not infringe privately owned rights. Referenve herein to any specific commercial product, process, or service by trade name, tradenark, manufacturer, or otherwise does not necessarily constitute or imply its endorsement, recorn. mendation, or favoring by the United States Government or any agency thereof. The views and opinions of authors expressed herein do not necessarily state or reflest those of the United States Government or any agency theroof.

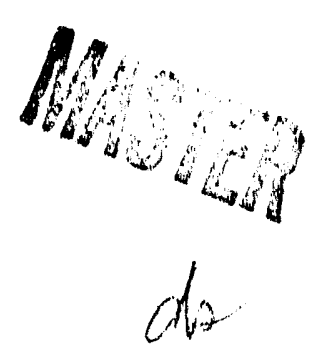




\section{SCORE AND OBJECTIVES OF WORK}

Scope:

The characterization of surfaces and surface chemistry is one of the most active and rapidly growing research areas in all of chemistry. A working knowledge of the surface structure and chemistry of coals is necessary to understand and inteligently optimize processes dominated by surface interactions. In applications such as coal cleaning and coal slurries, the interactions occurring at the coal surface are critical. In all chemical reactions of solid coal, the reagent must first encounter the coal surface. How much of the surface is open to a molecule and the interactions occurring on contact are important, often crucial parameters. Our present scientific understanding of the coal surface and its interactions are rudimentary and inadequate to support the development of new processes and to allow full understanding of the technology which has already been developed, largely on a trial-and-error basis.

\section{Objectives:}

The objectives of this work are to investigate the surface structure and surface interaction thermodynamics of a variety of coals and treated coals in order to develop an understanding of the coal surface and how it changes. The surface structure of coals will be analyzed by: 1) deposition of NMR relaxation agents to provide spectra of those atoms near the surface which yield direct information about the structure of the surface groups; (2) 
using ${ }^{1.29} \mathrm{Xe}$ NMR as a probe to determine pore' size distributions and the surface polarity of coals; and (3) mapping out the steep dependence of surface area on adsorbate size for a variety of coals. Thermodynamic studies of coals will studied by: 1) inverse gas chromatography to obtain full desorption isotherms of coals; and (2) to use classical calorimetric studies of coal surfaceadsorbate interactions to generate a thermodynamic data base.

\section{Present Work:}

our work this quarter has been the determination of: (1) the average micropore ciameter of three Argonne coal samples by ${ }^{129}$ Xe NMR spectroscopy; (2) the cyclopentane BET surface areas for the full series of Argonne coals. For a detailed discussion of the relationship between the ${ }^{129} \mathrm{Xe}$ NMR chemical shift and the pore diameter, see DE-AC22-89PC89757-1.

The ${ }^{129}$ Xe NMR chemical shift was measured as a function of $\mathrm{Xe}$ (g) pressure on Argonne: Pocahontas No. 3 ( $91 \% \mathrm{C}$, daf), Pittsburgh No. 8 ( $83 \% \mathrm{C}, \mathrm{daf})$, and Blind Canyon (79\% C. daf) coals. The coal samples were all desorbed overnight at $10^{-5}$ torr on a Micromeritics Digisorb 2500 stainless steel rig equipped with a diffusion pump and a Datametrics differential capacitance-type pressure sensor to measure $\mathrm{Xe}(\mathrm{g})$ pressures. All NMR spectra were obtained on a Brucker AM $500 \mathrm{MHz}$ NMR spectrometer operating at $138.3 \mathrm{MHz}$. The ${ }^{129} \mathrm{Xe}$ NMR chemical shifts are expressed relative to the free $X e(g)$ peak and are always positive. The ${ }^{129} \mathrm{Xe}$ NMR spectra in descending $\mathrm{Xe}(\mathrm{g})$ concentrations on 
the Argonne Pocahontas coal are shown in Figure 1. The peak furthest upfield is due to free $\mathrm{Xe}(\mathrm{g})$ and is assigned a chemical shift value of zero ppm. The downfield resonance, corresponding to $x e$ in the Pocahontas coal, shows an NMR chemical shift dependence on $\mathrm{Xe}(\mathrm{g})$ pressure and extrapolates to $162 \mathrm{ppm}$ at zero xe concentration. Applying the method developed by Demarquay and Fraissard ${ }^{1,2}$ to the pocahontas coal, a mean free path of $0.75 \AA$ was calculated, based on the center of the NMR peak. Assuming the coal pores to be spherical, an average pore diameter of $5.9 \AA$ is obtained for this coal. A spherical micropore model for all the coals was assumed based on evidence determined by SANs $^{3}$ and spin probe EPR methods.

The ${ }^{129} \mathrm{Xe}$ NMR spectra in descending $\mathrm{Xe}(g)$ concentrations on the Argonne Pittsburgh No. 8 and the Argonne Blind Canyon coals are presented in Figures 2 and 3 respectively. Based on the same rational and data treatment applied to the pocahontas coal, the Pittsburgh No. 8 coal shows a NMR chemical shift dependence on $\mathrm{Xe}(\mathrm{g})$ pressure and extrapolates to $171 \mathrm{ppm}$ at zero Xe concentration. This corresponds to a mean free path of $0.5 \AA$ for $\mathrm{Xe}$ in the coal pore, based on the center of the ${ }^{1.29} \mathrm{Xe}$ NMR resonance. Assuming spherical pores, an average micropore diameter of $5.4 \AA$ is calculated for this coal. coincidentally, the NMR chemical shift dependence on $X_{(g)}$ pressure extrapolates to $171 \mathrm{ppm}$ at zero Xe concentration for the Argonne Blind Canyon coal. This also corresponds to an average pore diameter of $5.4 \AA$ for the Argonne Blind Canyon coal. 
We have previously observed and reported a steep BET surface area dependence on adsorbate size for an Argonne Illinois No. 6 coal ${ }^{5}$. During this quarter, the cyclopentane BET surface areas were determined for the entire set of Argonne coals and presented in Table 1. All surface areas were determined on a Micromeritics stainless steel surface area instrument. The 5-point cyclopentane surface areas were measured at an adsorption temperature of $0^{\circ} \mathrm{C}$, allowing 24 hours equilibration time for the first point and 6 hours equilibration time for each subsequent BET adsorption point. 
F: -c 1. ${ }^{129}$ Xe NMR pressure dependener ectra of Argonne

Pocahontas No. 3 coal in descending $X_{(g)}$ pressure.
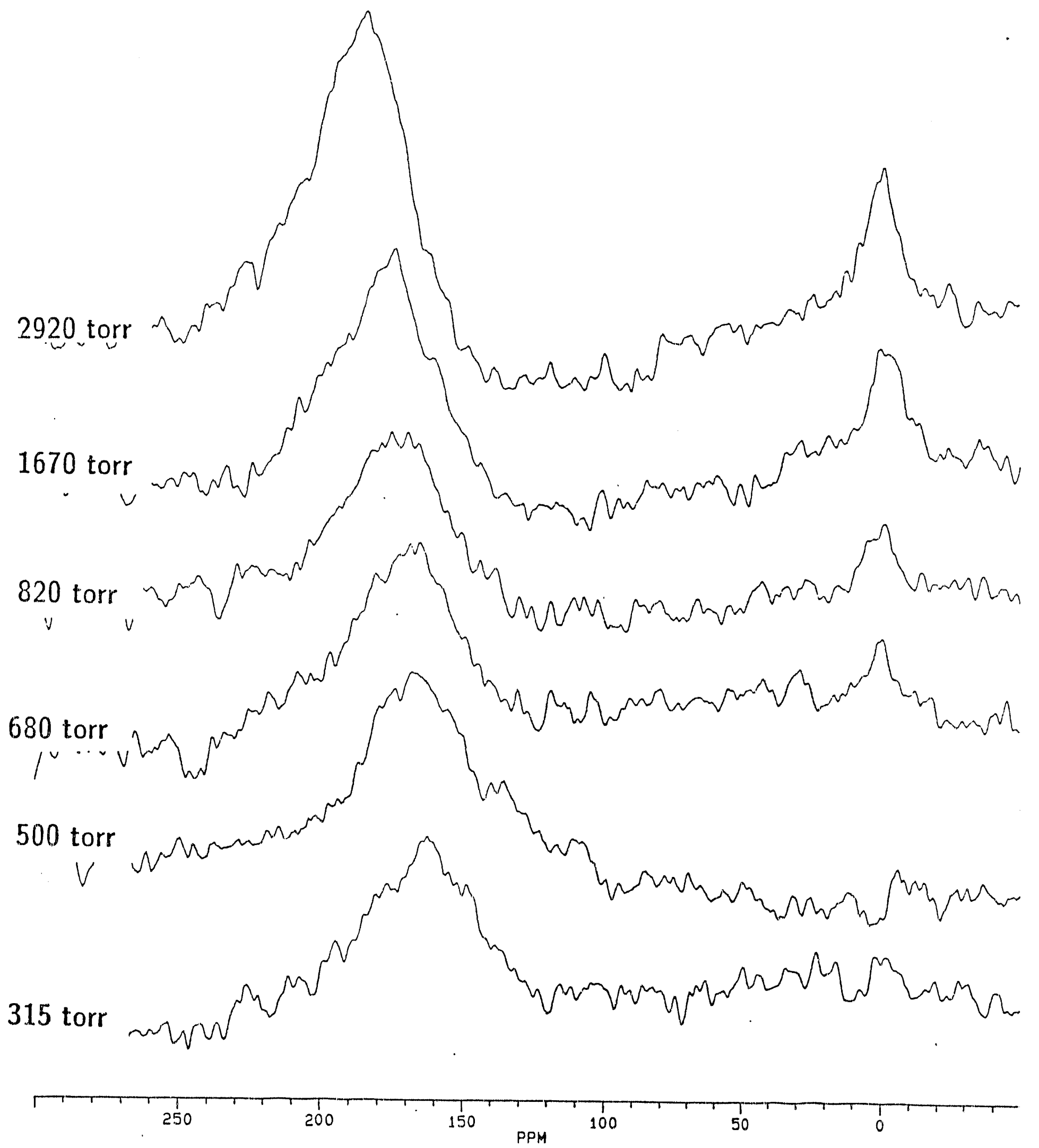
Figure 2. ${ }^{129} \mathrm{Xe}$ NMR pressure dependencr nectra of Argonne

Pittsburgh No. $8 \mathrm{coal}$ in descenung $\mathrm{X}_{(g)}$ pressure.

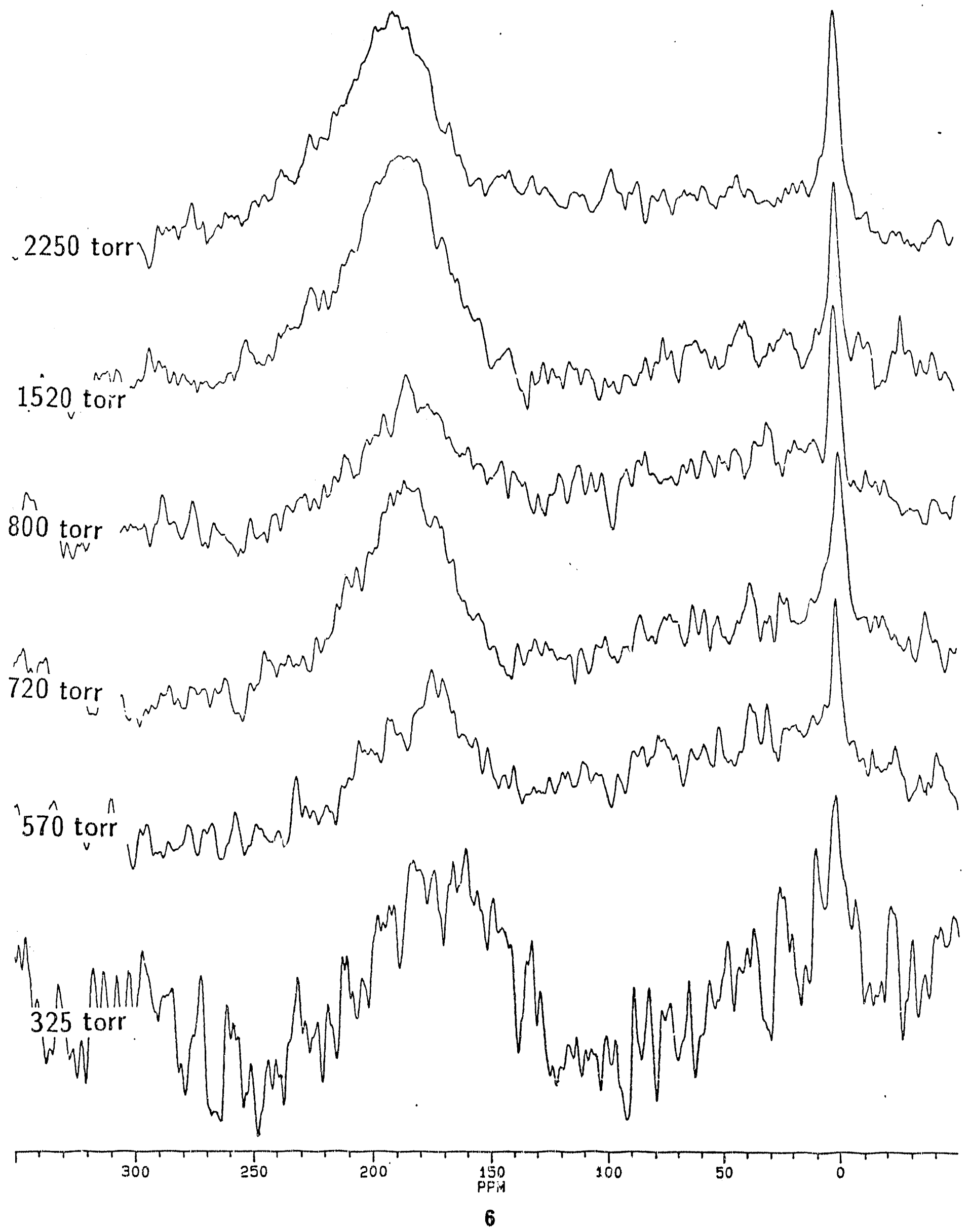


Figure: ${ }^{29}$ Xe NMR pressure dependence spect, $\quad$ Argonne Blind Canyon coal in descending $\mathrm{Xe}_{(g)}$ pressure.

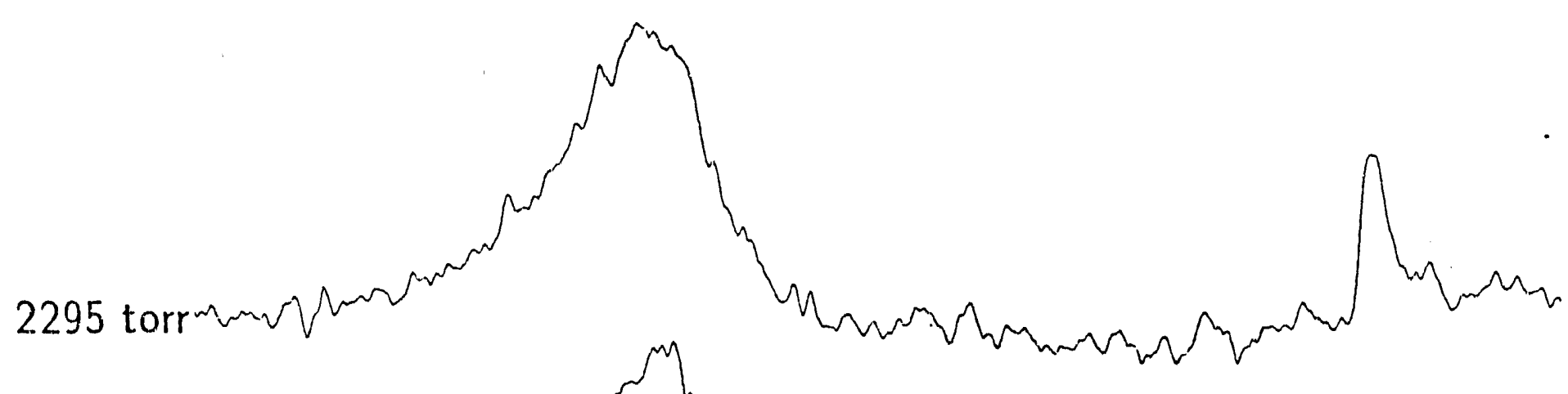

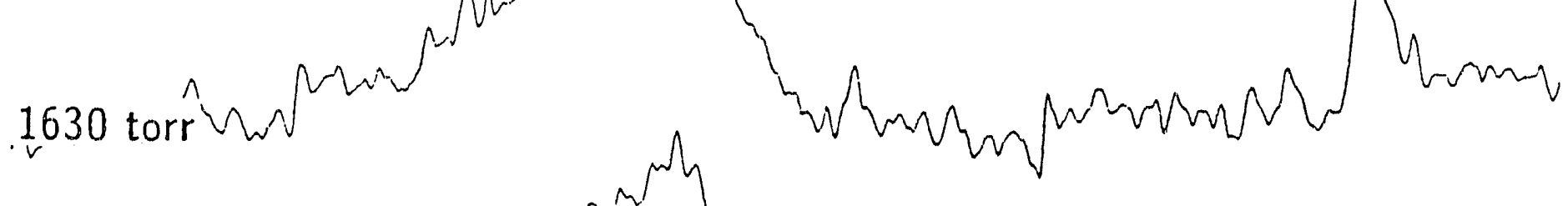

790 torr

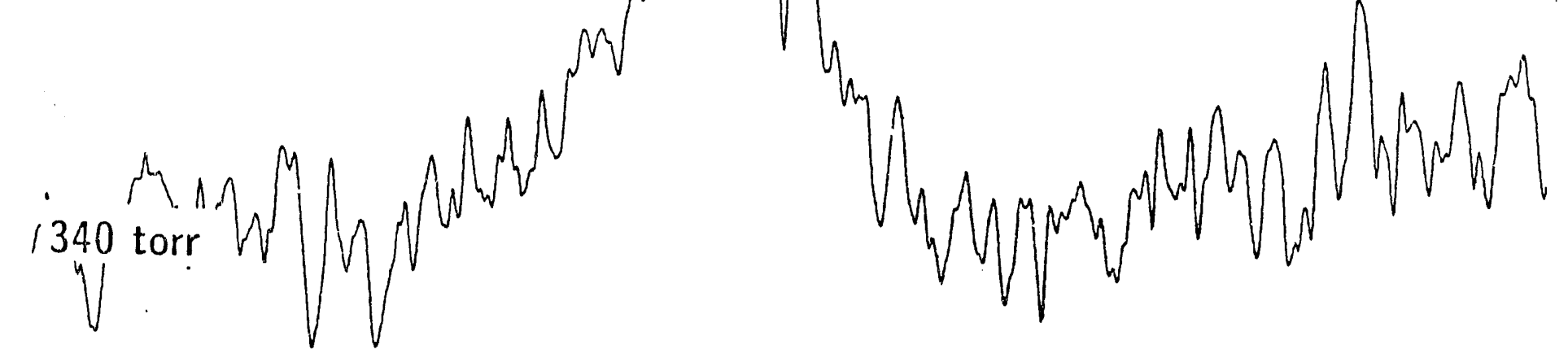

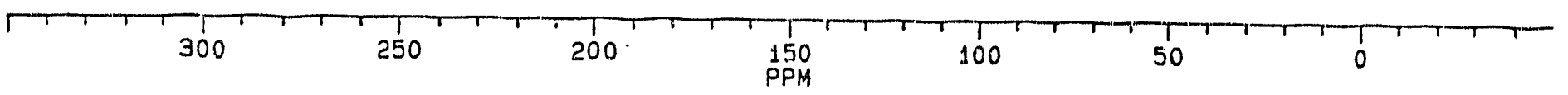




\section{REFERENCES}

1. Fraissard, J. ; Ito, T. Zeolites 1988, ․, 350-361.

2. Demarquay, J.; Fraissard, J. Chem. Phys. Lett. 1987, 136 (3,4), 314-318.

3. Winans, R. E. ; Thiyagarajan, P. Prepr. Pap. - Am. Chem. Soc., Div. Fuel Chem.1987, $\underline{32}(4), 227-231$.

4. Goslar, J. ; Kispert, L. D. Energy Fue/s 1089, 3, 589-504.

5. Larsen, J. W. ; Wernett, P. Energy Fuels 1988, 2, 710-720. 
Table 2. BET cyclopentane surface area of Argonne coals

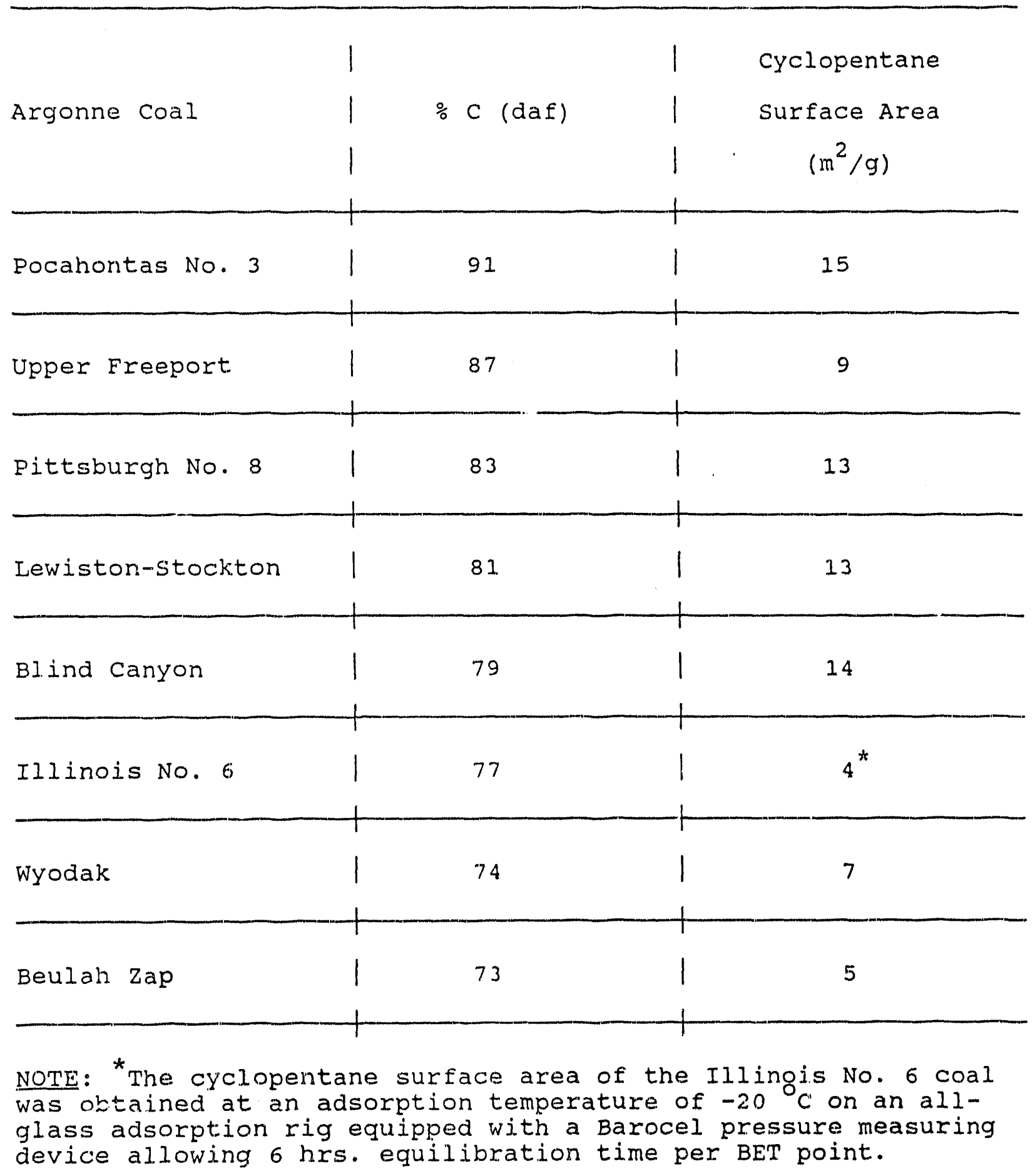



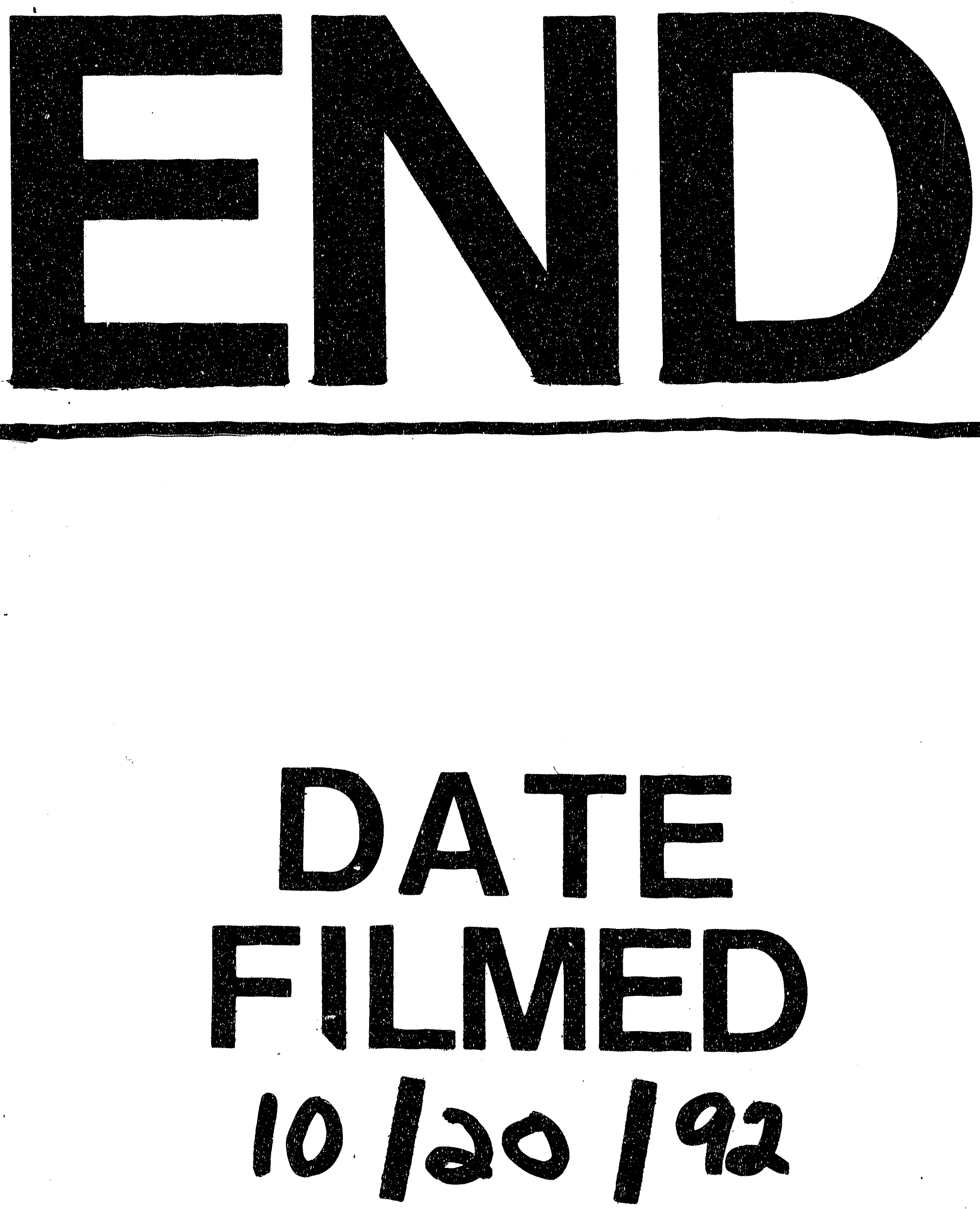


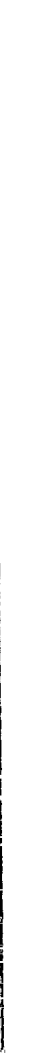

